Document downloaded from:

http://hdl.handle.net/10251/44814

This paper must be cited as:

Pennock-Speck, B.; Saz Rubio, MMD. (2013). A multimodal analysis of facework strategies in a corpus of charity ads on British television. Journal of Pragmatics. 49(1):38-56. doi:10.1016/j.pragma.2012.12.010.

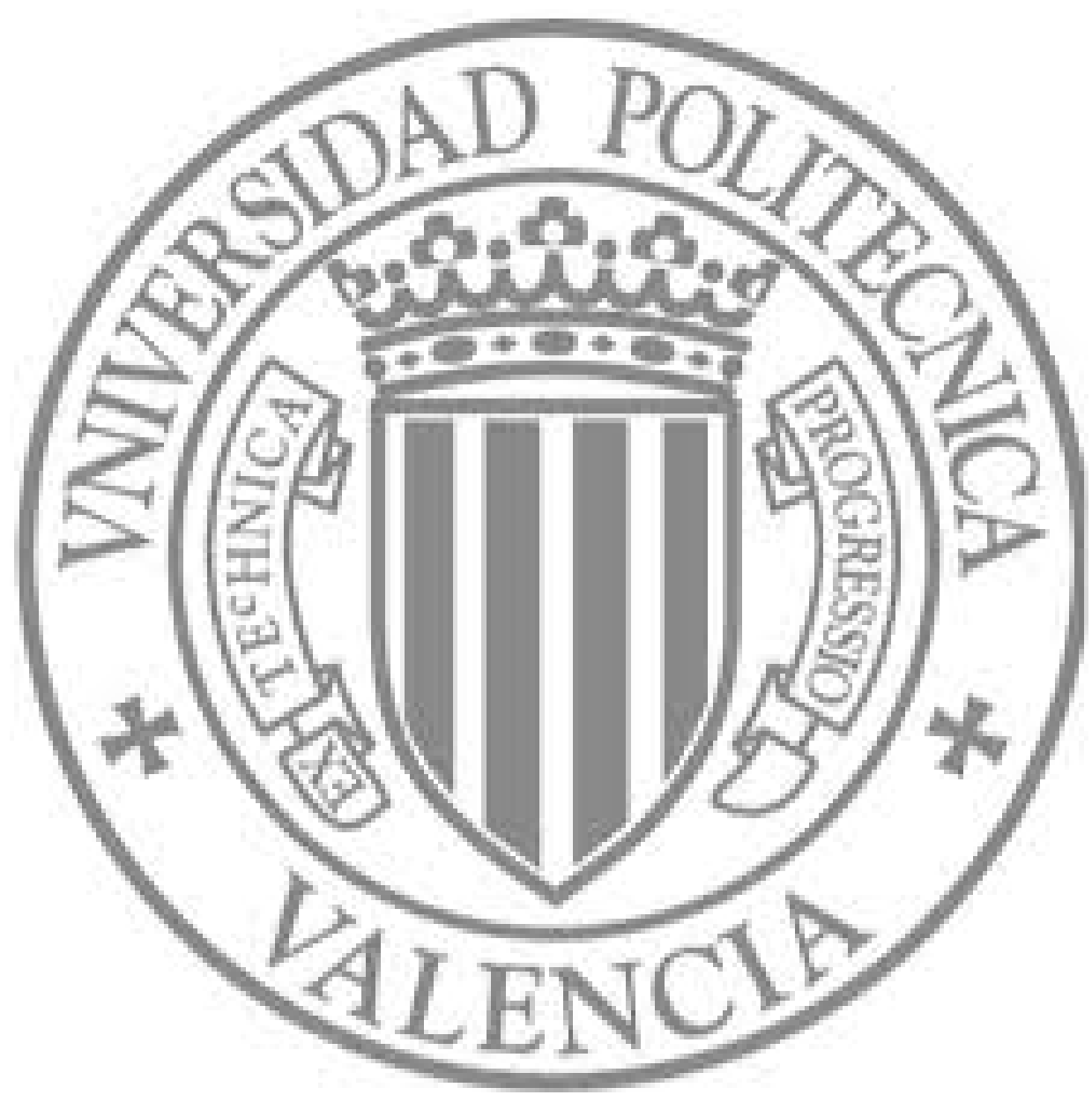

The final publication is available at

http://dx.doi.org/10.1016/j.pragma.2012.12.010

Copyright Elsevier 


\title{
A multimodal analysis of facework strategies in a corpus of charity ads on British television
}

\author{
Barry Pennock-Speck \\ Departament de Filologia Anglesa i Alemanya/IULMA \\ Universitat de València \\ Avda. Blasco Ibáñez, 32. 46010 Valencia. Spain. \\ Telf. +34 963864200 \\ Barry.Pennock@uv.es \\ $\mathrm{M}^{\mathrm{a}}$ Milagros del Saz-Rubio \\ Departamento de Lingüística Aplicada \\ Universitat Politècnica de València \\ Camino de Vera s/n. 46022 Valencia. Spain \\ Telf. +34 963877530 \\ masaru@idm.upv.es
}

\begin{abstract}
*Corresponding author: $\mathrm{M}^{\mathrm{a}}$ Milagros del Saz-Rubio, Departamento de Lingüística Aplicada Universitat Politècnica de València, Camino de Vera s/n. 46022, Valencia. Spain. Telf. +34 963877530, masaru@idm.upv.es
\end{abstract}

\begin{abstract}
The aim of this article is to carry out a qualitative multimodal analysis of the codification of verbal and nonverbal politeness strategies in a sub-corpus of five charity commercials aired on British television. Brown and Levinson's $(1978,1987)$ verbal politeness strategies are taken as a starting point together with a detailed analysis of facework that is realized through paralinguistic and extralinguistic modes of communication (Kress and van Leeuwen, 1996; Machin, 2010). In what we have identified as the problem phase of the commercial, our analysis has revealed that advertisers deliberately attempt to create threats to the viewer's positive and negative face by making him/her feel responsible for the plight of others. In all five ads, through multi-scene montage, positive and off-record politeness strategies are enacted involving vivid case stories, demand images, sad music and serious extradiegetic voices. These strategies also help convey the idea that the suffering of others might also affect viewers at some point in their lives and thus strengthen the bond between the characters depicted in the ads and those watching them. During the solution phase, in which images, melodies and voice-overs begin to become more upbeat, negative politeness strategies are used to soften the actual request to donate while positive politeness strategies are employed to appeal to the presupposed solidarity of the viewers. Our analysis points to the need to carry out further research on the interplay between verbal and non-verbal communication, especially in the field of politeness studies.
\end{abstract}

Key words: Facework; Multimodality; Charity ads; Guilt appeals; Montage;

\section{Introduction}

Vast amounts of money are spent on television commercials and, in spite of the growing importance of online marketing ${ }^{1}$, they are still the most important vehicle for

${ }^{1}$ http://www.forbes.com/sites/roberthof/2011/08/26/online-ad-spend-to-overtake-tv/ 
commercial and other messages and a worthy object of study. In particular, what interests us here is how TV ads engage the viewer. In this sense, the importance of advertisements in society cannot be underestimated. In the words of Williamson (1978: 11) they not only 'reflect' but 'mould' our lives and can seem more real than reality itself because our real experience is isolated '....while what is a universal experience is the impact of media and social images' (Williamson, 1978: 170 emphasis in original).

One way of engaging the audience of a TV ad is through the use of politeness strategies (Authors, 2009 based on Brown and Levinson, 1987 -henceforth B\&L). It is, therefore, our aim in this article to carry out a multimodal analysis of a corpus of charity ads broadcast on British television. These ads are significantly different from other ads in two ways. The first is that they deliberately set out to threaten the audience's face by attempting to make them feel guilty through short scenes featuring victims, or potential victims, of abuse or poverty in often quite distressing situations. The second is that, unlike most other TV ads, they actually ask the audience to carry out certain acts such as to donate money or blood in an overt way, which adds to the threats previously enacted.

In order to describe the politeness strategies in our ads we will use a multimodal approach which takes into account not only verbal messages but also paralinguistic cues such as voice-quality or intonation; and extralinguistic modes of communication such as format and structure, images, diegetic sound and music. Any analysis of television advertising that does not include all the relevant semiotic codes that are at play will miss out on important insights into how politeness strategies are implemented in this genre. Our analysis will be qualitative in nature. The main reason is that the number of charity ads we identified in our corpus of over a thousand TV commercials is quite small and is thus not suited to a quantitative approach. On the other hand, it does lend itself to a detailed appraisal of the politeness strategies at work in each of the ads.

Section two of this article outlines the main theoretical notions that inform our analysis and the characteristics of charity ads. Section three describes our corpus and presents our methodology of analysis. Section four contains our analysis and results of each of the modes which make up the ads. Section five draws conclusions.

\section{Theoretical Framework}

This article applies the politeness framework devised by B\&L to the analysis of TV charity commercials. In this context, most of the objections which have been raised regarding the $B \& L$ approach either do not apply or can actually be construed as advantages. Doubts concerning the universality of B\&L's politeness strategies and claims that they are skewed towards Western culture (e.g. Matsumoto, 1988; Ide, 1989; He and Zhang, 2011) are largely irrelevant as we are analyzing British TV ads. In fact, the image of a 'scheming western (prototypically Anglo-American) individualist‘ (O`Driscoll, 2007:468) fits many people's idea of what an advertiser is. It is precisely the scheming (in the literal sense) nature of advertising discourse that differentiates it from other types. So, even though B\&L's strategic and instrumental view of verbal interaction may be unrealistic when it comes to ordinary conversation (Eelen, 2001), it seems ideally suited to the premeditated discourse found in advertising copy. 


\title{
2.1. Brown and Levinson's framework of politeness
}

A key concept in B\&L's work is that of face (Goffman, 1967), i.e., the 'public selfimage that every member wants to claim for himself' (B\&L: 61). Following Durkheim's (1915:299-326) distinction between positive and negative rites, B\&L claim that face can be divided into:

\begin{abstract}
Negative face: the basic claim to territories, personal preserves, rights to non-distractioni.e. to freedom of action and freedom from imposition.

Positive face: the positive consistent self-image or 'personality' (crucially including the desire that this self-image be appreciated and approved of) claimed by interactants. (B\&L:

61)
\end{abstract}

B\&L categorize some acts (both verbal and non-verbal) as intrinsically threatening to the negative and/or positive face of both the speaker $(\mathrm{S})$ and the hearer $(\mathrm{H})^{2}$. Such Face Threatening Acts (henceforth FTAs) call for redressive action in the form of politeness strategies (B\&L:24). Thus, during social interaction, speakers rationally assess the seriousness of the FTA on the basis of three independent and culturally determined variables, i.e., the social distance (D) and social power (P) existing between $\mathrm{S}$ and $\mathrm{H}$, and the ranking of imposition (R) of the act itself. Any rational S will thus either seek to avoid any FTAs in her $^{3}$ interactions with $\mathrm{H}$, or employ certain strategies to minimize the threat that may occur during these interactions. B\&L present five hierarchically ordered strategies depending on the amount of facework required: first, S must decide whether to carry out the FTA or not. If she decides to go ahead, then the FTA can be done 'off-record', that is, by means of irony, hints, rhetorical questions, understatements, etc., or 'on record'. If the FTA is done on record, it can be performed without redressive action, or baldly, i.e., "Do X!". On-record FTAs with redressive action can take two forms depending on the aspect of face being emphasized, negative or positive, e.g. 'Would you please do X?' versus 'Darling, do $\mathrm{X}^{\prime}$.

Off-record politeness strategies (ORPSs) help speakers indirectly convey certain assumptions and thus avoid the potential responsibility or outcome derived from employing more direct strategies. Negative politeness strategies (NPSs) aim at the avoidance of imposing upon the addresee through attenuating or 'softening' mechanisms such as hedging, formality, impersonalization and nominalization, etc. Finally, positive politeness strategies (PPSs), being 'approach-based strategies', include the use of compliments, the seeking of agreement, joking, claiming reflexivity of goals, claiming reciprocity, and uttering expressions of sympathy and cooperation (Brown, 1998:85).

\footnotetext{
${ }^{2}$ We will keep the original terminology but obviously in TV commercials S refers to the advertiser and $\mathrm{H}$ to the viewers.

${ }^{3}$ We will alternate the use of male and female pronouns in each section.
} 


\subsection{Politeness and the discourse of TV advertising}

Previous research on the enactment of politeness strategies in TV ads (Authors, 2009; Author 1, 2000) has shown that advertising agencies strategically deploy PPSs pervasively 'as a kind of social accelerator' (B\&L:103). Through them S signals her desire to somehow 'come closer' to $\mathrm{H}$. The 'free-ranging' nature of PPSs (B\&L:129), whose action extends beyond individual FTAs, not only redresses threats to H's positive face but helps to preempt or soften any threats to H's negative face. In this vein, Authors (2009:2542) state that in advertising:

[...] the use of positive politeness strategies is geared towards the creation of an optimistic atmosphere that redresses the advertiser's intrusion into the audience's freedom of action, but that simultaneously makes the audience feel at ease and highlights group-identity.

The brief mention in B\&L of how gestures in some cultures constitute politeness markers, such as the drawing together of one's palms held vertically to show deference in India, pointed to the need to go beyond verbal politeness in discourse in general. This is even truer of an essentially multimodal genre such as TV advertising. As Authors (2009:2542) show with regard to positive politeness in commercials, the 'atmosphere of solidarity and camaraderie between the advertiser and the target group is best achieved through what is explicitly said through the voice-overs together with the visual imagery that accompanies the message and backs it up'.

The role of ORPSs is to offer advertisers a way of indirectly conveying certain claims about the product or its benefits without explicitly stating them (Authors, 2009:2535-2556). Authors (2009) also found that ORPSs were especially productive in commercials at the reward dimension, i.e., the elements in the ad that are meant to entertain the audience rather than inform them (Crook, 2004:734).

Regarding NPSs in this genre, Author 1 (2000, 2011) and Authors (2011) reported that attenuation strategies are not as common as PPSs and ORPSs. NPSs are used sparingly in commercial TV ads and are generally aimed at mitigating or attenuating the force of certain product-related claims in an attempt to offer the audience an escape route from the imposition that such claims might make on them.

\subsection{Politeness and Charity Advertising}

Charity advertising is big business whose essential aim is to raise funds, mainly through individual donations (Scott-Parker, 1989; Eayrs and Ellis, 1990; Hevey, 1992; Eayrs et al., 1995). It also serves to promote the 'brand image' of the charities advertised, and to increase public awareness of the issues they were created to tackle (cf. Barnett and Hammond, 1999: 309). 
One of the main traits of charity advertising, and of key relevance in this paper, is the ubiquitous use of guilt appeals ${ }^{4}$. These take the form of attention-grabbing devices such as distressing images (cf. Moore and Harris, 1996) and are designed to influence attitudes and trigger a desirable outcome on audience behaviour (cf. MacKenzie and Lutz, 1989; Hyman and Tansey, 1990), namely, the donation of money to the charity. The type of guilt triggered in our corpus of ads is of an existential nature ${ }^{5}$, (Huhmann and Brotherton, 1997) which mainly arises when one feels empathy for others as a result of being better off or more fortunate than them (for example when seeing a person in need or suffering from a terminal disease). Burnett and Lunsford (1994) also link this type of guilt to feelings of 'social responsibility' for possibly failing to assume our responsibilities towards others in society.

Regarding our view of how face is invested in TV ads, and, more precisely, in charity ads, some initial comments need to be made. If, as Arundale (2006:201) proposes, face is exclusively "an emergent property of relationships and therefore a relational phenomenon", the face of a solitary viewer of a TV ad could not be threatened or otherwise by a charity ad as interaction with $\mathrm{S}$, the advertiser/charity, is limited at best -some viewers do yield to the perlocutionary effect of these ads by making a donation while a very small number of viewers may write letters protesting about their content. If Arundale is right, our analysis of face threats in TV ads is not possible. However, we subscribe to the social/psychological account of face (Goffman, 1955) in which each individual has an essentially consistent self-image or identity that she, as it were, carries around with her, wherever she goes. Imagine an academic who makes a blunder in front of an audience of her peers; she would presumably lose face vis-à-vis the audience but also, and more importantly, her own positive self-image would be damaged. Proof of this is that a faux pas during a talk on pragmatics in a conference, for example, might lead to the speaker abandoning the thought of giving more talks in public. The reason is, that although a new group of listeners would not know about the original blunder, the speaker would. So, face in the Goffman sense is part of one's psychological make-up, it doesn't just appear in interaction with others. When B\&L say that their Model Person (MP) is "endowed" with face wants (B\&L:58), it is difficult to see how these might just suddenly appear every time that the MP is involved in interaction.

Thus, the role of face in charity ads is as follows. $\mathrm{H}$, a solitary viewer, is watching a charity ad and being subjected to harrowing images and verbal descriptions of suffering. We assume $\mathrm{H}$ has an image of herself as a caring, compassionate person and, presumably, she has enough money to contribute but is as yet is not doing so. As a consequence, a feeling of guilt might be growing in her due to the contradiction between her self-image and her lack of action. The most obvious way to resolve this clear threat to her positive face

${ }^{4}$ Guilt appeals are common tools in the achievement of promotional objectives within contexts such as fundraising, public health and safety (Huhmann and Brotherton, 1997; Hibbert et al., 2007).

5The other two primary types of guilt are reactive and anticipatory. Reactive guilt arises when one's own standards of what acceptable behavior is are infringed. On its part, anticipatory guilt concerns the consideration of going against one's own standards of what acceptable behavior is (cf. Huhmann and Botherton, 1997). 
is to make a contribution to the charity, or at least, to think about doing so. We also posit that $\mathrm{H}$ will feel that her negative face is being threatened by a demand or request to donate money or other goods that she has not actively sought out and that such an action, therefore, encroaches on her personal freedom of action, her negative face wants.

From the perspective of what kind of facework is enacted there are normally two stages. The first seems to be designed to threaten both H's positive and negative face; the former by questioning H's willingness to help others -her altruism- through PPSs and ORPSs (see section 4) and the latter by impinging on H's freedom of action. In spite of the face-threatening nature of this discourse, we do not see it as a case of impoliteness because making $\mathrm{H}$ feel uncomfortable is not the same as being impolite to her, that is, to "cause offence" (Culpeper, 2011:23).

In the second, cathartic, stage ORPSs and PPSs are used to depict $\mathrm{H}$ as a caring person who might potentially be willing to donate money, thus attending to her positive face. Within this second stage and, unlike other types of ads where the mention of monetary transactions is almost totally avoided, most charity ads are characterized by relying on more or less overt requests or pleas to have individuals donate money to a certain cause. Once more, within B\&L's framework for FTAs, making requests or pleas poses a threat to H's negative face (B\&L, 1987:65-66) and as such, some amount of redressive facework, normally in the form of NPSs, is expected on the part of S.

Thus, our interest in this paper lies in how $\mathrm{H}$ is, as it were, deliberately importuned through verbal and nonverbal stimuli in the first stage of the ad but also how advertisers implement positive and negative facework strategies to attend to H's face in the second.

\section{Corpus and methodology of analysis}

\subsection{The Charity sub-corpus}

We have included the term 'corpus' in the title of this article due to its importance from an epistemological point of view and because only by using a randomly chosen corpus can there be some guarantee of the validity of one's results. This is important as we wish to say something about charity ads as an identifiable sub-genre of TV ads rather than describe an individual artifact such as a political speech, a film, or a play. Opting to analyze a series of ads means that it is possible to isolate one or more features, whether they are verbal or non-verbal, that the members of a (sub-)genre might have in common, an approach which Forceville (2007) defends.

The collection of charity ads has been taken from the Multimedia Analysis of TV ads corpus (henceforth MATVA), which consists of 1,285 TV ads recorded during four days from the British TV channels ITV1 and Channel 5. The corpus includes the transcription of spoken and written discourse, on the one hand, and a description of the various dimensions of para- and extralinguistic elements of the 608 non-duplicated ads.

From the MATVA corpus we have identified a total of sixteen charity ads which represent registered charities in the UK. However, the total of number of non-duplicated ads is smaller as five of the charity ads are found twice in our corpus, leaving a total of eleven distinct ads. Due to space restraints, we have omitted the analysis of three of the eleven ads as they are shortened versions of longer ones and practically identical to the 
longer versions. From the eight ads left we have selected one of the three NSPCC ads (the Miles version) and just one of the two Blood.co.uk ad (Man picking up his daughter) for our analysis. The three remaining ads are DogsTrust, Save the Children and Macmillan Cancer.

\subsection{Methodology of analysis}

Our corpus of charity ads is admittedly tiny when compared to others such as the British National Corpus but it is unique in that we know of no other corpus of television ads like ours. Size does matter in one respect, however, which is why we have chosen to carry out a qualitative analysis of our ads rather than a quantitative one, even though Bowker and Pearson (2002:48) point out that a corpus of specialized language such as ours 'represents a more restricted subset of natural language' and can therefore be smaller than other corpora. Size is not the only reason for choosing a qualitative analysis approach. Given the multimodal nature of our corpus it would be hard to envisage how music, voice types, images and other non-verbal aspects of ads might be turned into numbers and averaged out or converted into statistics. It might be possible medium by medium, for example, counting the number of times an image of a woman appears, for instance, but not if we wish to say something about the cumulative effect of a number of semiotic modes.

Cook (2001:42) sums up the paradox of attempting to handle multimodality in print ads, but especially in TV ads, when he states that we must take into account the pictorial and musical components involved in them but that, as analysis is carried out in words, and words cannot capture completely the essence of an image or music, the task is nigh on impossible. Cook (2001: 43) points out that some researchers solve this problem by ignoring it. However, we believe words can at least sketch the influence of semiotic modes other than verbal language. Even Poyatos (2002: 49), whose three volumes on non-verbal communication are proof enough of the importance he gives to all the semiotic modes involved in human interaction, gives testimony to the unique capacity of language proper to describe the information conveyed by any or all of them. We are not, on the other hand, as optimistic as Thibault (2000) and Baldry (2004), who seem to believe that new advances in computer programmes are the answer to the problems mentioned by Cook (2001). Their use of tables in Baldry and Thibault (2006), in which each column shows a different dimension of TV ads such as: 'visual frame' (including still images), 'visual transitivity', 'camera position and movement', etc., helps the reader to get a better idea of what is happening in the ad. However, it is the inability to provide sound that really demonstrates that we still rely to a great extent on translating images, sounds, voice types, etc., into written language. For the purpose of this article, we analyse each mode more or less separately but keeping them completely apart is both impossible and counterproductive. Notwithstanding this, we see no benefit in supplying the readers of this research with what might be irrelevant, often non-verbal, minutiae which might obscure the phenomena that are really important to the current paper. Therefore, our tables, located in the Appendix (AT1 to AT5), merely help give the reader of this article an overall impression of the structure, images, voice, sound and music in our five ads. 


\section{Analysis and results: a multimodal analysis of politeness strategies}

This section has been divided into three subsections: structure and format, sounds and images, and verbal communication in order to focus more fully on how politeness strategies are enacted or enabled through each of these semiotic modes. To facilitate the comprehension of each subsection, what follows is a list of the politeness strategies we have identified in our corpus.

Positive Politeness Strategies fall under two main strategies:

a. Claim common ground

PPS1 Notice, attend to H (her interests, wants, needs, goods) (B\&L: 103)

PPS2 Exaggerate (B\&L: 104)

PPS3 Intensify interest to H (B\&L: 106)

PPS7 Presuppose, assert, raise common ground (B\&L: 117)

b. Convey that $\mathrm{S}$ and $\mathrm{H}$ are co-operators

PPS9 Assert or presuppose S's knowledge of and concern for H's wants (B\&L: 125)

PPS10 Offer/promise/Give gifts to H (goods, sympathy, understanding, cooperation) (B\&L: 129)

PPS11 Be optimistic (B\&L: 126)

PPS12 Include H and S in the same activity (B\&L: 127)

PPS13 Give or ask for reasons (B\&L: 128)

Off-Record sub-strategies are organized around two main types:

a. Invite conversational implicature, via hints triggered by violation of Gricean Maxims

ORPS1 Give hints (B\&L: 215)

ORPS2 Give association clues (B\&L: 215)

ORPS10 Use rhetorical questions (B\&L: 223)

b. Be vague or ambiguous

ORPS13 Overgeneralize (B\&L: 226)

Negative Politeness Strategies are grouped under the following main strategies:

a. Be direct

NPS1 Be conventionally indirect (B\&L: 132)

Don't presume/assume

NPS2 Question, hedge (B\&L: 145)

b. Don't coerce $H$

NPS3 Be pessimistic (B\&L: 173)

NPS4 Minimize the imposition (B\&L: 176)

NPS5 Give deference (B\&L: 178)

c. Communicate S's want not to impinge on $\mathbf{H}$

NPS8 State the imposition as a general rule (B\&L: 206)

\subsection{Ad structure and format}

Four of our ads, NSPCC-Miles, Blood.co.uk, MacMillan Cancer Support and Save the Children are made up of just two main phases divided into several sub-phases. These 
phases dictate, to a certain extent, the distribution and type of politeness strategies implemented. The first phase of the text (Baldry and Thibault, 2006: 47) which we call the 'problem phase' describes the problem the charity has to combat. The second is 'the solution phase' in which the audience is requested to do something in order to solve the problem. The cathartic final sequences within this phase generally take up a small proportion of each ad and normally finish with an almost empty screen, a short VO and some OST which includes contact information and the organization's logo, as is the case in the ads for Blood.co.uk (AT1: 25-30), MacMillan Cancer Support (AT4: 22-30), and Save the Children (AT5: 35-40) ${ }^{6}$.

The only ad which deviates from this general structure is the DogsTrust ad which starts with the first of two parts of the solution phase, including requests for money, followed by a dramatic narrative that takes the form of a flashback showing the predicament of Harry, the dog, before arriving at DogsTrust (AT3: 21-32). This narration constitutes the problem phase of this ad, as it aims at inducing a feeling of guilt in the audience while also serving as a justification for the previous overt requests to donate money. The ad concludes with the second part of the solution phase that also includes a request for money. So, even though the structure is slightly different from that of the other four ads, the overall effect pursued is equivalent.

In Authors (2009), the idea that TV ads were made up of just one format was eschewed as it was found that hybridization and blending of ad formats is the norm in TV advertising. Thus, an encompassing twofold distinction was proposed which subsumed Stigel's (2001) division into two main ad formats ${ }^{7}$ : i) lecture+fiction and ii) fiction+lecture. The first format encompasses those ads where: 'the fictional component, consisting of an action sequence, mini-drama, or montage, “is controlled and bound together" by a VO (Stigel, 2001:330). On the other hand, the fiction+lecture format foregrounds the presentation of a mini-drama or montage followed normally, but not always, by a short final VO.

Montage is the overwhelmingly dominant format employed in our sub-corpus ${ }^{8}$. It can be described as being made up of paradigmatic sign relations, that is, 'exemplars of a shared semantic class' in opposition to syntagmatic sign relations that have some spatial or temporal connections (Larsen, 2005:162). In other words, montage constitutes a juxtaposition of shots of, in our case, different characters in different contexts, whose connection is not immediately obvious. Each shot, in relation to other shots, is extradiegetic, which Messaris (1997:171) defines as 'going outside the story'. However, they become diegetic, or part of a longer story, when taking into account the ad as a whole. The relevance of each shot to the others obviously necessitates the interpretative collaboration of $\mathrm{H}$. The search for relevance is aided by cues such as music but especially

\footnotetext{
${ }^{6}$ See tables in Appendix for a more detailed description of the solution phases of ads.

${ }^{7}$ Stiegel (2001) and Jantzen and Stiegel (1995) identified ad formats on a factual-fictional scale. These two categories were each made up of three formats of presenter, voice-over, testimonial (factual) and voice-over + , drama and montage (fictional).

${ }^{8}$ The short versions of the NSPCC which we have not included here are comprised of only one very short scene. They are broadcast a short time after the long versions to reinforce their message.
} 
by VOs and OSTs. Unlike the montage found in other genres, where associative and lyrical 'moods' abound, in TV ads the onus is on reinforcing a verbally delivered message.

The extensive use of montage in our corpus of charity ads is exemplified by the MacMillan Cancer Support commercial. Here the problem phase involves three sub-phases in which different characters are reminded of cancer in their daily routines (AT4: 0-4, 4-12, 12-18). Montage enables the advertiser to expose the audience to a series of weak implicatures that suggest that cancer can happen to anyone, perhaps even to $\mathrm{H}$. It also allows the advertiser to gradually build empathy between cancer sufferers and $\mathrm{H}$. In this sense montage can be seen as a delivery system for ORPSs and PPSs. However, instead of redressing FTAs, these strategies actually threaten H's positive and negative face through exposure to uncomfortable facts and images. This pattern is repeated in all the other ads. For instance, we see a series of individuals who will need a blood transfusion (Blood.co.uk); a succession of abused children (NSPC Miles); numerous abandoned dogs being taken care of (DogsTrust) and scenes of starving children (Save the Children).

\subsection{Sounds and images}

The role of sound and music -or for that matter any kind of non-verbal communication in TV ads in general- is that they act as a reinforcement of the verbal message; they never supply the main message. As Wilson and Wharton (2006: 26) point out, they work by 'facilitating the retrieval of certain types of syntactic, semantic or conceptual representation' yet by themselves are incapable of providing anything near unambiguous meaning. In ordinary conversation, according to Goffman (1969:14), we 'give' impressions through words but simultaneously impressions are 'given off' through our involuntary kinetic and paralinguistic gestures. These impressions might even contradict what is said; for example, a particular intonational contour might lend insincere overtones to an apology, whether the insincerity was real or not. In TV ads it is also possible that the impressions 'given off' might not achieve the ends aimed for. However, unlike ordinary face-to-face interaction, the instrumental nature of the communication in TV ads means that any apparent contradiction between what is communicated verbally and non-verbally will generally be intentional and will seek some kind of effect such as irony. It is, therefore, essential to take non-verbal semiotic modes into account, which is the purpose of this section.

There are many similarities, beyond format, in the use of non-verbal modes of communication among the ads in our corpus. Essentially, they reinforce the effects sought after in each phase, i.e. the discomfort of the problem phases and the relief offered in the solution phases. Such effects, discussed in more detail in section 4.3, are mainly achieved through ORPSs and PPSs which all the non-verbal stimuli contribute to.

We will start our description of the non-verbal elements in our ads with music. Like other non-verbal resources, it is difficult to attach a precise meaning to a particular type of music although minor chords, for example, are often found in in what can be described as sad music. Music in TV ads often plays the same role as that of the musical score of a film, i.e., it may set off a schema in the background but the action and the dialogue, that is, the VO, are foregrounded (van Leeuwen, 1999:19). Cooke (1959) has argued that in 
contemporary music different kinds of melodies, harmonies, instrumental sounds and vocal styles all carry meanings. In turn, these are often connected to emotional states and relate to other resources, such as images (Tagg, [1982:4] cited in Machin, [2010:98-9]). This is a fact that advertisers are very aware of.

For reasons that could be summed up by the word 'decorum', melancholy or sad music dominates four of our five ads precisely because the problem phase lasts longer than the solution phase. The gloomy atmosphere provided by the music is one of the most salient clues of the existence of some kind of problem and underlines the verbal message in each ad. The DogsTrust ad is exceptional in that it features mostly upbeat music in a major tonality. However, half way through, the music shifts to a minor chord for a few refrains, giving a melancholic feel to the flashback narrative sequence that makes up the problem phase (AT3: 21-23, 23-29) ${ }^{9}$, reinforcing the overall effect that other modes are contributing to the phase. Regarding the Blood.co.uk ad, melancholy music predominates. However, the last note which is heard just as the words Do something amazing (AT1: 29) appear on screen, is a dominant seventh which transmits a sensation of hope to the solution phase. The NSPCC Miles ad features sad music throughout but right at the end there is a perfect cadence with the melody, also playing the tonic note, $\mathrm{C}$, to give it a completely resolved feeling which coincides with the equally resolute words: Together we can help stop cruelty to children. Full stop (AT2: 45-60). Sad music, expressed through arpeggiating minor chords, is also predominant in the MacMillan ad although it modulates to a more upbeat parallel major right at the end of the problem phase (AT4: 18-22), adding a hint of hope that continues into the solution phase. The Save the Children commercial highlights a very clear use of music to separate the problem phase from the solution phase. It begins with a minor sound, adding violins for extra emphasis, but once the narrator says: It doesn't have to be this way (AT5: 20-40), a major chord is played and this triumphant major sound carries on until then end.

Paralinguistic features such as intonation and voice quality also play an important role in our ads. All but the DogsTrust ad (see section 4.3) feature mature, deep serious male voices $\mathrm{VO}^{10}$. The sombre and serious tone is prevailant in the problem phase -once again, probably due to reasons of decorum- but becomes more upbeat during the solution phase. For example, in the MacMillan Cancer Support commercial, the words: So that some days it's not all about cancer. It's about life (AT4: 18-22) signal the beginning of the solution phase. As a result, optimistic semantic content is reinforced by a more upbeat tone in the VO which, in turn, is reinforced by a simultaneous change to more cheerful music. A supplicatory tone is heard in several ads, Blood.co.uk: Please don't leave it to someone else; NSPCC-Miles: Sometimes we need to open our eyes to the suffering that's all around us; Save the Children: It really doesn't have to be this way. In all these cases, such tones of supplication signal the transition to the solution phase while acting as an introduction to the NPSs that follow in the form of requests (See section 4.3).

\footnotetext{
${ }^{9}$ We would like to express our thanks to Matthew Warner and Marina Fuster-Font for their help with the musical terminology we have used.

${ }^{10}$ Voice-over labels are taken from the main MATVA corpus and was carried out by a series of British university student informants in their twenties.
} 
Diegetic sounds generally play a secondary role in our corpus, that is, the sound of cars and a ball being kicked around in the problem phase of the MacMillan ad simply accompanies the images to provide them with a hint of reality. They can, however, be significant as when the child being fed by her mother laughs out loud towards the end of this same ad (AT4: 18-22) because this is accompanied by both optimistic statements, voice tone, and music, all of which signal a move to the next phase. In the NSPCC-Miles commercial, Miles' whimpering pronunciation of mama, the sound of a malfunctioning bulb, footsteps approaching another child called Josie, the thump of a fist on the table and the sound of a video game in the background, point to the suffering and neglect that the children who appear are going through. All these auditory clues are part of the PPS3, that is, heightening of interest to $\mathrm{H}$. Another significant example is the whirring of a film projector displaying how Harry the dog in the DogsTrust ad was abandoned in a dirty caravan (AT3: 21-29). The noise of the projector together with the darkness of the screen with its blurred images enhances the sensation of melancholy conveyed by the verbal message to create the appropriate atmosphere for the request that will come seconds later.

We have already mentioned images when we looked at how our ads are split into phases. Here we will concentrate on the use of very short sequences of images that aid in the building up of guilt appeals addressed to the audience. We will focus on the following three dimensions of visual representation: (i) gaze, that is, whether characters look directly at the viewer or away from him; (ii) angle of interaction, as 'the angle from which we view a person can suggest different relations between the people represented and the viewer', for instance, associations of height and power (Machin, 2010: 113); and (iii) distance, or 'the association of physical proximity and intimacy' (Machin, 2010: 116) between the represented participants and the audience.

The microsequences in which the characters seem to gaze into the viewer's eyes are of key interest in the codification of facework. Kress and van Leeuwen (1996, 2006:117), drawing on Halliday (1985), defined them as 'demand looks' as they encourage the audience to initiate some sort of engagement with the participant represented in the image. In our corpus these are often children who 'lock eyes' with the viewer at certain strategic moments in the ads. For example, in the NSPCC Miles ad, a demand look initiates the problem phase. A close up of Miles (AT2: 0-8), looking straight into the camera enhances our chances of identifying with his situation (Figure 1). A zoom shot of Miles' face transmits physical proximity and intimacy and can be interpreted as a plea for help, especially considering the simultaneous contextual cues conveyed by the VO and the OST.
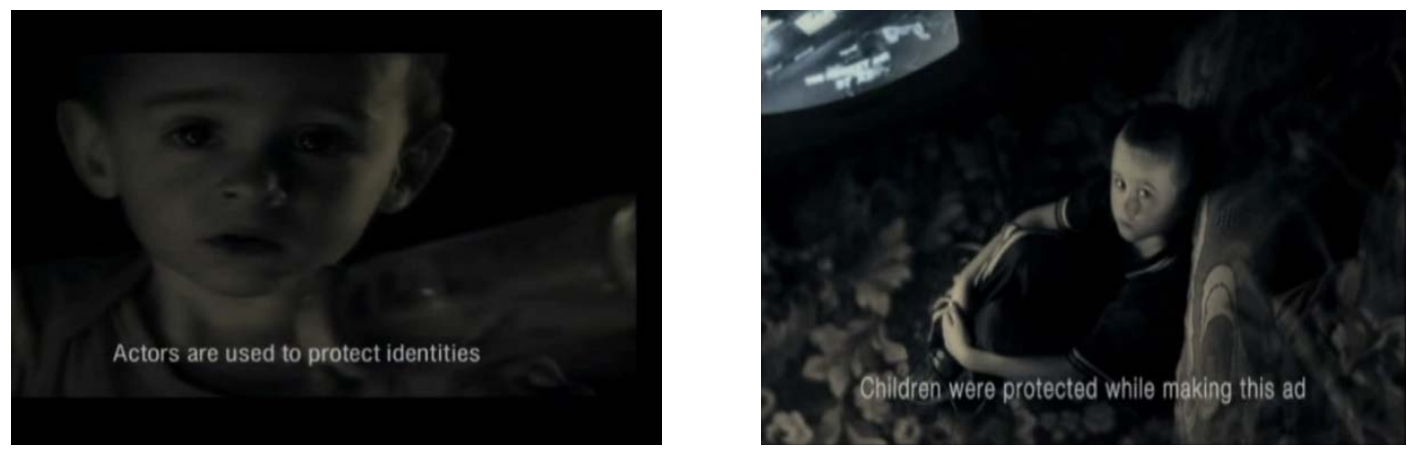
Figure 1: Miles

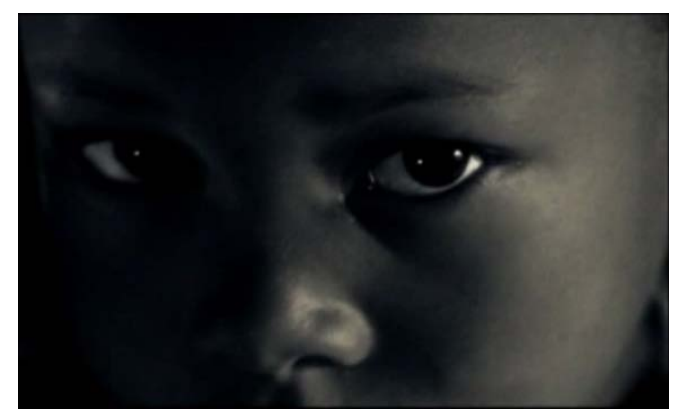

Figure 3: Josie
Figure 2: Tom

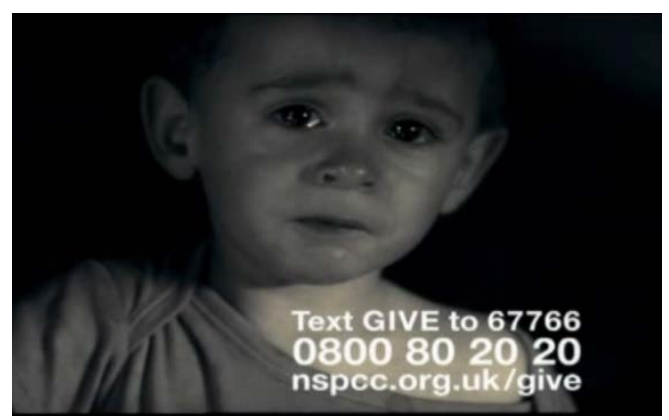

Figure 4: Miles

As the ad moves on, there is a scene in which Tom (AT2: 19-24 - Figure 2) looks up at us, which suggests helplessness. We contend that the advertiser wishes to stir in $\mathrm{H}$ feelings of being potentially responsible for Tom's situation as the verbal and non-verbal signals act together to form part of an ORPS. The next macrosequence depicts an extreme close-up of Josie's eyes (AT2: 8-15 - Figure 3). She looks at us fixedly the moment the voice-over pronounces the word 'a fist', hinting at some type of physical violence (see the ORPSs in section 4.3.1 below). Finally, in the solution phase, we are confronted with another close-up of Miles who looks at the camera with teary eyes (AT2: 45-60 - Figure 4). Our view of him is frontal, facilitating our identification of the ordeal he is going through. This microsequence coincides with the VO requesting the audience to give just two pounds a month. Similarly, in the Save the Children ad there is an extreme frontal close-up of an African child eating while the VO asks We save the children, will you? The covert invitation to donate is reinforced by the demand look of the child implicitly asking for our help (ORPS1). To sum up, demand images strategically build up a suitable context in which to make guilt pleas or requests for action more difficult to ignore for the audience.

\subsection{Verbal dimension}

In the Blood.co.uk commercial, scenes one and two, and the beginning of the third, constitute the sub-phases of the problem phase (AT1: 0-7, 7-14, 14-25). In this phase, we are shown normal people involved in daily, routine activities: a father waiting to pick up his daughter, a woman happily chatting at the hairdresser's and a man looking in on a child sleeping in a cot. However, towards the end of each scene an OST appears that warns of tragic or life-threatening events to come (motorway pile-up, chemotherapy, livertransplant). From a facework perspective, these scenes are examples of ORPSs, in particular, ORPS1, 'give hints'. The combination of apparent contentedness and foreboding through the polyphony generated by the interplay between OST and VO may suggest to $\mathrm{H}$ that she should become a donor because she herself, her family or friends may be involved in accidents or may need surgery at some point in their lives. Given the time constraints of a TV ad, a montage is a very efficient way of hinting that we all may be in need of blood some day (ORPS1). Association clues (ORPS2) are also present because both $\mathrm{S}$ and $\mathrm{H}$ 'mutually know' (B\&L: 215) that these scenes are a build-up to the request for help that 
follows in the solution phase. ORPS1 and ORPS2 make up the backbone of the problem phase in all the ads we have analyzed. The first phase of this ad can also be interpreted as an example of PPS3, where interest to $\mathrm{H}$ is intensified as the $\mathrm{S}$ presupposes we are, or might be, concerned about having an accident, suffering from cancer, or seeing our loved ones suffer.

Up to this point $\mathrm{H}$ is not asked directly to do anything through VOs or OSTs. Hints and intensification of interest might be enough in most kinds of ads to forward the advertiser's agenda of placing a product in the public eye but in the case of this charity commercial the advertiser must make sure that $\mathrm{H}$ knows why she should help, where she can donate money, or, in this case, blood. This is the function of the solution phase made up of the final four seconds of scene three in which we see the man turning from the cot with a sleeping infant to a cot that is empty. Simultaneously we see the OST Liver transplant and hear (AT1: 14-25):

VO: Give blood and you can save someone’s life today. Please don't leave it to someone else.

The initial VO starts with a bald-on-record request addressed to $\mathrm{H}$ in the form of the imperative: Give blood, which might be interpreted as impolite. However, imperatives are efficient from a communication point of view and through them: ' $\mathrm{S}$ can claim that other things are more important than face, or that the act is not an FTA at all' (B\&L, 1987: 72). They are also a way of 'avoiding the further imposition of prolixity and obscurity' (B\&L, 1987: 131). Moreover, an imperative is not face-threatening if it is in the interest of $\mathrm{H}$, i.e., using the phrase 'come in' to invite someone into a room or when it is used to encode socalled alter-centred politeness (cf. Haverkate, 1994).

Interestingly, Give blood is followed by: and you can save someone's life which gives explicit reasons for being a blood donor and softens the imperative somewhat ${ }^{11}$. This corresponds to PPS13 - giving or asking for reasons. The use of this strategy also enhances H's positive face by highlighting H's ability to save lives. This utterance is also followed by the appearance of please in the phrase: Please don't leave it to someone else (AT1:1825) which heightens the supplicatory tone of the request. The importance of the word please should not be underestimated as it is only found in the charity sub-corpus of the MATVA corpus. The word please is embedded in a NPS5 that implies giving deference. The following scene centres on the charity's logo made up of two hearts (AT1: 25-30) where we see the OST: 030012323 23/NHS blood.co.uk./Do something amazing.

We interpret Do something amazing ${ }^{12}$ as an invitation to $\mathrm{H}$ to get involved in a good cause of an alter-centred nature by using exaggeration, that is, PPS2. In other words, S attends to H's positive face by implying that she is a valuable member of society who has the ability to help others in need. Thus, $\mathrm{S}$ enhances H's positive face by investing in her the power to help and to contribute to the cause of giving blood, one which is also beneficial for her as a member of society. The overall effect conveyed by these politeness strategies is

\footnotetext{
${ }^{11}$ One of anonymous reviewer has suggested that imperatives such as 'Give blood' or 'Save the Children' constitute well-known slogans, which may help decrease their threatening force in TV ads.

${ }^{12}$ In the other Blood.co.uk ad from our corpus, the verbal elements in the solution phase are exactly the same.
} 
reinforced by the fact that the sad and melancholy progression of piano chords, which helps set the serious tone during the problem phase, reaches its highest note when the request Don't leave it to someone else is made (AT1, 25-30). This makes the piece especially poignant and strikes a note of optimism which continues to the end of the commercial, thus helping mitigate the requests present in the solution phase.

The next ad, NSPCC-Miles, is, along with the two other NSPCC ads, the most harrowing of our small corpus. The problem phase (AT2: 0-8, 8-15, 15-19, 19-24) consists of a series of scenes showing the plight of three young children, Miles, Josie and Tom described in section 4.2. As in the Blood.co.uk ad, the problem phase constitutes a PPS3, i.e., an intensification of interest to $\mathrm{H}$ through dramatic scenes including images, music, voices and diegetic sound. It also involves the same verbal strategies as in the Blood.co.uk ad even down to the polyphony of the VOs and OSTs (AT2: 0-24):

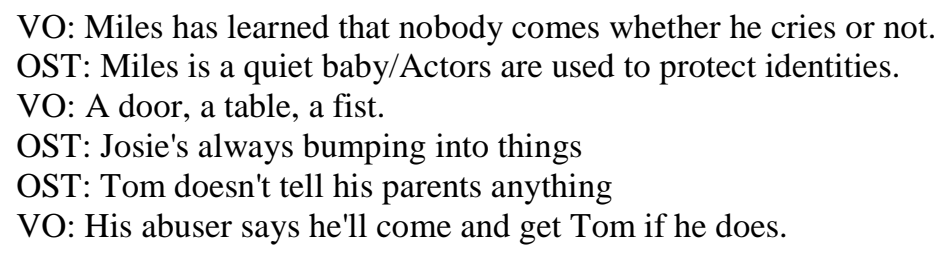

The solution phase starts with a hint (ORPS1), contained in the VO (AT2: 24-27), that we should take action: Sometimes we need to open our eyes to the suffering that's all around us and work together to stop it. The pronunciation of the words open our eyes is made to coincide with the OST: open your eyes [our emphasis], which is a more direct way of addressing $\mathrm{H}$, although the imposition is mitigated as the request is not voiced in a more salient way, that is, through a VO. This is a 'personal-centre switch' from S to H (B\&L: 117), an instance of PPS7. As such, it asserts common ground, reinforcing the idea that we all share responsibility in cases like that of Miles.

In the next series of VOs (AT2: 30-34, 34-41) several instances of NPSs mitigate the request for money starting with a NPS5 expressed through please and followed by a hedge, just, (NPS4) which minimizes the importance of the imposition. The tone of the voice is one of overt supplication during this phrase Please open your eyes and your heart (AT2: 34-41).

The following three verbal interventions (AT2: 41-45), a VO and two OSTs, contain the imperatives text, call, and give, while $\mathrm{H}$ is confronted with Mile's direct gaze that strengthens the appeal for money in an indirect but effective way. The OST: Cruelty to children must stop ${ }^{13}$ is presented as a generalization and, therefore, it comes across as quite indirect (NPS8, state the FTA as a general rule). It also diverts the pressure away from $\mathrm{H}$, who is no longer exclusively responsible for doing too little to prevent these children from suffering. It can also be read as a reason for supporting the $£ 2$ a month appeal and, as a consequence, functions as a justification or PPS13. Finally, in the last scene (AT2: 45-60)

\footnotetext{
${ }^{13}$ These exact words are found in the two other full-length NSPCC ads and in the shortened versions. Also please is found in all five of the ads not analyzed here.
} 
there is a personal-centre switch PPS7 in the VO which suggests the existence of common ground between $\mathrm{S}$ and $\mathrm{H}$ and a common interest in the cause: Together we can help stop cruelty to children. Full stop. Let us start now. It is precisely when these words are uttered, that the piano becomes subtly more upbeat, thus reinforcing the effect of this PPS.

The DogsTrust ad is very complex both in terms of format and structure, as we pointed out in section 4.1. It is made up of three phases: solution, problem, solution; the first and last are of the montage type while the problem phase is a sad mini-drama narrated by Harry who tells us the story of how he was abandoned (AT3: 21-23, 23-29). Ads which use both montage and mini-drama are very rare in the larger MATVA corpus. The first and final phases contain clear examples of PPS3, i.e., intensifying interest to H (B\&L:106). In naturally occurring conversation, interest to $\mathrm{H}$ would be achieved 'by making a good story' through the use of the vivid present and directly quoted speech (B\&L: 106-107). The same strategy is used in TV ads and enhanced with images and sound. Of course, another purpose of making the communication interesting is actually to make the ad more memorable, which is obviously one of the main aims of TV ads. The DogsTrust ad provides another good example of a PPS3 delivered through images of 'happy' dogs involved in different activities, proving that a politeness strategy does not have to be verbal at all. Given the solution-problem-solution structure of this ad, requests for help begin right at the beginning through OST and the VO while we are shown scenes of contented dogs (AT3: 0-4):

OST: Please sponsor a dog/DogsTrust Registered Charity Numbers: 227523 SC03784.

VO: Hi, I'm Harry. I live at DogsTrust. Will you sponsor an abandoned dog like me and help them find out what love really is? It's only a pound a week so please visit sponsoradog.org.uk now.

OST: Please sponsor a dog/DogsTrust Registered Charity Numbers: 227523 SC03784.

Once more, the word please is found in the OST (NPS5). In the VO that follows, the requests directed at $\mathrm{H}$ include several mitigating devices such as Will you sponsor ... instances of NPS1, that is, 'be conventionally indirect'. The adverb in the same excerpt, only, is an NPS4, i.e., 'minimize the imposition' (B\&L, 1987: 176) that introduces the request with 'please' that follows. All the hedges we have found are hedges of quality (B\&L, 1987: 166) like only, which soften the imposition, that is, the amount of money to be donated.

A sudden shift to sadder music signals the beginning of the problem phase in this ad. There is a noticeable change in the narrator's (Harry's) tone of voice, suggesting melancholy enhanced by images of him staring out of a run-down caravan. Although there is no request in the testimonial itself (AT3: 21-29, OST) the appearance of the words love is ... a sponsor like you comes across as an off-record request for help (ORS1) aided by the shift to sad music.

Harry's words Luckily I was brought to DogsTrust marks the beginning of the second solution phase (AT3: 29-32). The whole excerpt is pronounced with a markedly optimistic tone of voice which contributes to the transmission of PPSs conveying solidarity with the audience, especially dog lovers. The following sentence starting When you're a sponsor ... is a clear example of PPS11: Be optimistic. Here 'S assumes that H wants S's wants for $\mathrm{H}$ (or for $\mathrm{S}$ and $\mathrm{H}$ ) and will help him to obtain them' (B\&L, 1987: 126). Here, it 
is presumed that $\mathrm{H}$ might want to become a sponsor, especially after considering the reasons provided (PPS13: DogsTrust rescue thousands of dogs a year and almost all dogs find a new home) and the insignificant cost of the donation (only a pound a week), which is mitigated with the hedge only (NPS4).

In the MacMillan Cancer Support ad images of cancer sufferers who are continuously reminded of their illness lend an ominous tone to the problem phase: an old lady sees the word cancer on the label of dress in a shop window, a young man on a football, a young mother on the kitchen clock. The choice of montage, together with sad piano music, enables the advertiser to suggest that cancer can happen to anyone, thus reminding $\mathrm{H}$ that the problems of cancer sufferers must be shared with people who understand them. Simultaneously, the different scenes which make up the montage highlight S's concern for H's values 'Presuppose H's values are the same as S's values', that is, PPS7 (B\&L, 1987: 123). This idea is reinforced through the utterances below (AT4: 0-18). These have an apparently informative appearance but their cumulative effect is the creation of a feeling of in-groupness and/or solidarity with $\mathrm{H}$. They offer support and include both $\mathrm{S}$ and $\mathrm{H}$ in the activity (PPS12, inclusive we) in case $\mathrm{H}$ may have money worries, the need to talk, or concerns about the future. By presenting the audience with the phrase we're here, S states her knowledge of and concern for H's needs (PPS9) and offers support. This type of declaration is typical among intimates and is strategically deployed by $\mathrm{S}$ to get closer to $\mathrm{H}$ and to convey the idea that both are 'in the same boat'.

However, redress is more specifically achieved through the use of when... structures (see below) in which $\mathrm{H}$ is addressed directly through the you pronoun -except for the first VO in which you is implicit. McMillan Cancer Support presents itself as willing to help $\mathrm{H}$ through bad times and linguistically emphasizes the fact that the $\mathrm{S}$ empathizes with $\mathrm{H}$ (AT4: 0-18):

VO: When cancer causes money worries, we're here.

OST: We are Macmillan Cancer Support./ 0800500800./www.macmillan.org.uk

VO: When you need to talk to someone who understands, we're here.

VO: And, when you're worried about the future, we're here. At Macmillan Cancer Support, we're here for you.

The verbal element in the solution phase is accompanied by a change to more upbeat music. This is the least imposing ad face-wise in our corpus because overt, direct requests for monetary aid are not made at all. The $\mathrm{H}$ is simply asked to get in touch with the organization and this comes right at the end when the relationship with the audience has been carefully established on the basis of empathy and camaraderie. The only bald-onrecord requests is for $\mathrm{H}$ to call a number and visit a website, through two imperatives call and visit (AT4: 18-30):

VO: So that some days it's not all about cancer. It's about life.

VO: Call us on 0800500800 or visit www.macmillan.org.uk

Although Macmillan Cancer Support is a traditional charity, this particular ad shares some of the traits of institutional advertising insofar as its main aim is to make the citizen aware of certain health-related issues, cancer in this case. 
The last ad in our corpus, Save the Children, is also made up of a problem/solution structure. The problem phase, a montage, shows four separate scenes of children suffering from malnutrition (AT5: 0-3, 3-7, 7-14, 14-23). It could be described as a series of hints on the ease with which malaria could be avoided (ORPS1). A serious and ominous tone is conveyed through the use of a male VO, the sad strings of the adagio-type of music and the following VO and OST (AT5: 1-7):

VO: Every day 24,000 children die needlessly. That's one child every three seconds.

OST: 24000 children will die today.

The potential request for money to call and give money (AT5: 7-14) is softened with the hedging device just in the phrase A mosquito net costs just $£ 3$ and could save her life (NPS4).

The use of hints and overgeneralizations in the problem phase could be viewed as giving $\mathrm{H}$ an escape route in B\&L's terms, as she may choose to think that the problems that are addressed in the ad do not concern her. However, even though the whole sequence of verbal messages in this phase is very indirect, the attempt on the part of the advertiser to make the viewers of these scenes feel slightly guilty at not donating the paltry sums of money mentioned in the ad is clear. The appeal to guilt is further reinforced through the use of demand images, such as that of Tanzie looking straight into the camera.

The solution phase starts with the transformation of the slow, sad adagio music to something a little more upbeat. A more optimistic tone of voice is found in the VO phrase It really doesn't have to be this way (AT5: 20-23). It could be defined as an overgeneralization (ORPS13) in which $\mathrm{H}$ 'has the choice of deciding whether the general rule applies to him in this case' (B\&L, 1987: 226). The appearance of more positive images completes the transition from problem to solution phase. We are shown a child being cared for by an adult with a Save-the-Children waistcoat followed by scene featuring another child eating with his mother. In the next two scenes we see an African man with a red Savethe-Children t-shirt tending to a child and a close up of a young child eating. It is in the solution phase that VOs contain requests to call and give money on the basis that $\mathrm{S}$ and $\mathrm{H}$ share a common interest, or PPS7, i.e., that of helping children in desperate need. We find vocabulary and strategies found in other ads in our corpus, such as the use of please (NPS5) and hedging devices (NPS4) to soften the imposition: Please call 08000729550 and give just (NPS4) £3 a month (AT5: 23-29). Through the VO, S also attends to H's positive face. In other words, $\mathrm{S}$ invites $\mathrm{H}$, a caring and able person who is presumably willing to put an end to such suffering, to join in the same activity (PPS12) when he says: We save the children, will you? that includes a tag question, which constitutes a NPS2 (AT 33-35).

\section{Conclusions}

In our multimodal analysis of the codification of facework strategies in our corpus of charity ads we have made several interrelated discoveries that suggest that such ads constitute an easily recognizable sub-genre of TV ads. One of the disadvantages of using a corpus, compared to analyzing one or two (or even more) handpicked members of a particular genre, is that the results will never be totally homogeneous. Nevertheless, we 
have shown that the five TV ads we have analyzed show significant similarities similarities which are shared with the rest of the three full-length and short TV ads in our corpus. The most important advantage that a finite corpus like ours affords is a certain guarantee of objectivity.

Regarding our results, we have identified two phases in charity ads. The first is the problem phase, in which $\mathrm{H}$ is confronted with an issue that needs to be dealt with; generally through a series of scenes showing the suffering and deprivation of the target group that the charity is dedicated to helping. The second is the solution phase in which answers are given to the problems that have been raised and requests are made for money, blood, or for sufferers to get in touch with the charity organization. With regard to the function of these phases, the 'negatively framed' (Chang and Lee, 2011) problem phase normally implies that, to some extent, the problem focused on is due to the inaction on the part of $\mathrm{H}$.

The advertiser's intention is to increase empathy between $\mathrm{H}$ and the needy recipients featured in the ad through guilt appeals of an existential nature (Smith and Berger, 1996) and ideally provoke in $\mathrm{H}$ a positive response in the shape of a donation. The solution phase is made up of optimistically framed messages which appeal to the giving potential of prospective donors. The messages are accompanied by non-verbal stimuli including positive images, voice tone and music.

As regards facework, the existence of these two phases has been shown to dictate to a great extent the verbal and non-verbal strategies employed by the advertiser. Our analysis has revealed that the problem phase in our ads poses a difficulty for B\&L's view of politeness strategies in that it shows that facework has uses other than exclusively mitigating FTAs (O'Driscoll, 2007: 478). In this phase clear instances of PPSs and ORPSs do not seem to be designed to redress FTAs but actually appear to create them. PPSs heighten interest in the problem and underline common ground between the sufferers and $\mathrm{H}$, while ORPSs hint that $\mathrm{H}$ is in a position to help to avoid or alleviate such suffering. It is this combination of PPSs and ORPSs within the montage in each ad, which signals that the problems experienced in the ads could befall all of us while suggesting that we have a responsibility to act upon them. The prevalence of montage affords the advertiser the opportunity to present to $\mathrm{H}$ the various situations the charities exist to remedy and the solutions offered within a short space of time. Moreover, by using montage it is left to $\mathrm{H}$ to relate the individual scenes to each other and come to an understanding of their meaning through a set of weak implicatures. In this way, montage aids in the non-verbal conveyance of PPSs and ORPSs.

The Solution Phase of the charity ads fits better into B\&L's view of politeness strategies as the numerous NPSs we have identified do what they are supposed to do, namely, mitigate direct emotionally-charged requests for money or blood. The occurrence of NPSs in ten out of the eleven charity ads in our sub-corpus constitutes a very important discovery in the study of politeness in TV advertising in general. In commercial ads proper, the only NPSs we find hedge claims about the product. Requests in commercial ads are normally bald-on-record because the level of imposition is low, i.e., they generally only ask $\mathrm{H}$ to call a number, visit a website, etc. However, NPSs expressing thanks, which entails humbling S's own face, (B\&L: 67) are simply not found. Through our analysis it also becomes clear that, although they are reinforced through other semiotic modes, NPSs in TV 
ads are generally conveyed verbally because they address specific FTAs unlike the more free-ranging PPSs.

Up to now we have concentrated on S's strategies to mitigate face threats directed at $\mathrm{H}$ but, at least, a brief mention is needed of the strategies implemented to protect S's own face. The first question that arises is who or what $\mathrm{S}$ represents in our charity ads? Our answer is that it is the charity itself because the ideal advertiser is an invisible mediator whose function is to promote a brand. The second question is whether a charity can possess face. Strictly speaking, only humans can. However, it often happens that animals, football clubs, governments, nations, brands are talked about in anthropomorphic terms; face, or its loss, being two of them. In fact, anthropomorphic research is a well-established marketing technique to elicit informants' opinions on products in terms of human qualities. It is thus easy to imagine advertisers designing an ad in terms of enhancing a brand's positive face. Having said this, it is difficult to envisage a brand having negative face which is basically the want to be unimpeded. Our use of face for non-human entities was never envisaged by B\&L nor was the application of their approach to advertising or, for that matter, to empirical research in general. ${ }^{14}$ However, analyzing S's face in TV ads is a valid extrapolation of B\&L's original endeavours as the attribution of human characteristics behaviour to brands is a common advertising strategy.

If we accept that charities can possess positive face, our first problem is that they seem to deliberately relinquish their own face wants. They appear to be happy to humble and abase themselves, something which is normally face-threatening and therefore avoided in our culture -although it is not uncommon in others ${ }^{15}$. For Eelen (2001:102) obviating one's own face wants is always a contradiction as 'wants qua wants can never explain their own non-fulfillment' [original emphasis]. However, being humble, just like being impolite, may on occasion satisfy S's. In this respect, it is important to take into account a priori goals. Altruistic organizations such as charities exist to raise money, to get people to be blood donors, or to offer assistance to sufferers, etc. To do this those in charge emphasise the plight of the people they are trying to help and the importance of the role of the potential donors/viewers. Their own role is downplayed, that is, they deliberately put themselves in the position of a powerless, albeit reliable interlocutor because to a certain extent their success, their face in the real world, depends on them being humble and altruistic. This is the demeanour (Goffman, 1956:489) expected of them by society. The vocabulary that makes up some of the NPSs found in our charity corpus such as please and thank you are not found in the commercial advertising in our larger MATVA corpus. As we mentioned before, this is because of the emotional nature of the requests being made. Another reason for the vocabulary in this type of NPS may be that the ranking of the imposition is greater than in other ads as charities are asking for something that is not of immediate benefit to $\mathrm{H}^{16}$. In the case of commercial ads, the lack of NPSs, is not only because the negative face of $\mathrm{H}$, the viewer, is hardly threatened compared to what happens

\footnotetext{
14 'Our strategies (...) do not necessarily provide sensible categories for quantitative research’ (B\&L: 21-22)

15 'Humiliative' forms are common in the Urdu of Dehli muslims: 'Please bring your ennobling presence to the hut of this dustlike person sometime' (B\&L: 179)

${ }^{16}$ We would like to thank one of our anyonymous reveiwers for this insight.
} 
in charity ads but because $\mathrm{S}$, the brand being advertised, cannot afford to 'humble and abase itself'. To include words like please and thank you, along with images and intonation that suggest supplication on S's part, might give the impression that the company's products and services are perhaps not quite as good as they should be. Being indirect, that is, using vague PPSs and ORPSs, helps to save S's face in the event that $\mathrm{H}$ is not interested in the product or service being promoted. In other words, it gives the brand an escape route.

One failure in politeness studies in general, and one which we have attempted to fully address in this article, is to ignore or sideline non-verbal communication. The inadequacy of treating communication as a series of separate speech acts while ignoring non-verbal semiotic modes is especially problematic in any thorough analysis of TV ads. It is precisely the need to look beyond what is linguistically codified in TV ads which, we hope, sets our analysis of politeness strategies apart from previous ones and makes it more integrative. Two examples should suffice to illustrate our point. In the NSPCC Miles ad a particular speech act such as Please open your our eyes and your heart (AT2: 34-41), which enacts an ORPS, cannot be divorced from the image of baby Miles or the supplication in the voice that utters the words. An even clearer example is provided by the Blood.co.uk ad in which images of a father contentedly waiting for his daughter is immediately followed by the OST Motorway pile up. This is clearly a hint (ORPS) juxtaposing images of happiness (non-verbal) with an ominous statement (verbal) in order to get people to give blood.

What our analysis has also shown is that the term 'communication act' is a more apt description of what is happening in these ads than 'speech act'. Apart from the non-verbal dimension of communication that this choice of label advocates, it suggests a more socially oriented view of spoken interaction than that provided by speech act theory (cf. Streeck, 1980; Levinson, 1983; Goodwin and Duranti, 1992; Hill and Irvine, 1992; Sbisà, 2001; Wee, 2004); in other words, one where the social context and what goes on between people (how participants interpret speech-acts and respond to them) is taken into consideration. ${ }^{17}$ In this respect, the communication acts in the ads we have analyzed are part of larger structures, or phases, which might be better described as macro-communication acts with a clear perlocutionary effect, i.e., to persuade the audience to do what is requested of them.

Finally, our analysis has shed light on the nature of charity ads but it also pinpoints a need to carry out more research on the interplay between verbal and non-verbal communication in general but especially in the field of politeness studies. Most importantly, it may even call for a rethink of B\&L's politeness strategies as mere devices to redress threats to positive and negative face.

\footnotetext{
${ }^{17}$ We would like to thank one anonymous reviewer for providing us with valuable references on the label 'communication act' and by pointing out its value in multimodal studies.
} 


\section{Appendix}

\begin{tabular}{|c|c|c|c|c|}
\hline \# & & $\begin{array}{l}\text { Voice-Over: Male/25-40/ } \\
\text { RP+/deep-serious }\end{array}$ & On-Screen-Text & Music \\
\hline $0-7$ & $\begin{array}{l}\text { Man waiting outside school } \\
\text { to pick up daughter. OST } \\
\text { appears at \#5 }\end{array}$ & & $\begin{array}{l}\text { Motorway pile-up/ } \\
\text { Thursday } 7.52 \mathrm{pm}\end{array}$ & \multirow[t]{4}{*}{$\begin{array}{l}\text { Gymnopedie type } \\
\text { slow, soft piano }\end{array}$} \\
\hline $7-14$ & $\begin{array}{l}\text { Women laughing while } \\
\text { getting hair done in } \\
\text { hairdresser. OST appears at } \\
\# 11\end{array}$ & & $\begin{array}{l}\text { Chemotherapy } \\
\text { Monday 10am }\end{array}$ & \\
\hline $14-25$ & $\begin{array}{l}\text { Man putting baby in a cot. } \\
\text { Then looks at empty cot } \\
\text { next to the first one. }\end{array}$ & $\begin{array}{l}\text { \#18 Give blood and you } \\
\text { can save someone's life- } \\
\text { today. Please don't leave it } \\
\text { to someone else. }\end{array}$ & $\begin{array}{l}\text { \#18 Liver transplant/ next } \\
\text { Tuesday 7am }\end{array}$ & \\
\hline $25-30$ & $\begin{array}{l}\text { Blood.co.uk logo of a red } \\
\text { heart and a white heart. }\end{array}$ & $\begin{array}{l}\text { Type your postcode into } \\
\text { blood.co.uk }\end{array}$ & $\begin{array}{llr}0300 \quad 123 \quad 23 & \text { 23/NHS } \\
\text { blood.co.uk./Do something } \\
\text { amazing }\end{array}$ & \\
\hline
\end{tabular}

Appendix Table 1: Blood.co.uk- Man Picking Up Daughter

\begin{tabular}{|c|c|c|c|c|c|}
\hline$\#$ & & $\begin{array}{l}\text { Voice-Over: Male/25 to } \\
\text { 40/RP/deep-serious }\end{array}$ & On-Screen-Text & Dialogue & Music \\
\hline $0-8$ & $\begin{array}{l}\text { Miles moves around in the } \\
\text { dark in his cot calling for } \\
\text { his mother. He drinks from } \\
\text { an almost empty bottle. We } \\
\text { here the buzz of a } \\
\text { malfunctioning light bulb. } \\
\text { Close up of his face }\end{array}$ & $\begin{array}{l}\text { Miles has learned that } \\
\text { nobody comes whether he } \\
\text { cries or not. }\end{array}$ & $\begin{array}{l}\text { Miles is a quiet } \\
\text { baby/Actors are used to } \\
\text { protect identities }\end{array}$ & $\begin{array}{l}\text { Mama, } \\
\text { mama }\end{array}$ & $\begin{array}{l}\text { Sad, } \\
\text { soft } \\
\text { piano } \\
\text { music } \\
\text { and } \\
\text { string }\end{array}$ \\
\hline 8-15 & $\begin{array}{l}\text { We see a small black female } \\
\text { child hugging a toy. Then } \\
\text { we are shown a close up of } \\
\text { her looking directly at the } \\
\text { camera. }\end{array}$ & A door, a table, a fist. & $\begin{array}{l}\text { Josie's always bumping } \\
\text { into things }\end{array}$ & & \\
\hline $15-19$ & Black screen & & $\begin{array}{l}\text { Tom doesn't tell his } \\
\text { parents anything }\end{array}$ & & \\
\hline $19-24$ & $\begin{array}{l}\text { Tom on floor looking up in } \\
\text { dark room with television } \\
\text { on showing a video game. }\end{array}$ & $\begin{array}{l}\text { His abuser says he'll } \\
\text { come and get Tom if he } \\
\text { does. }\end{array}$ & $\begin{array}{l}\text { Children were protected } \\
\text { while making this ad }\end{array}$ & & \\
\hline $24-27$ & $\begin{array}{l}\text { Dark screen (possibly } \\
\text { related to what is said in } \\
\text { VO) }\end{array}$ & $\begin{array}{l}\text { Sometimes we need to } \\
\text { open our eyes to }\end{array}$ & Open your eyes & & \\
\hline $27-30$ & $\begin{array}{l}\text { Tom pulls the bed cover } \\
\text { over him. }\end{array}$ & $\begin{array}{l}\text { the suffering that's all } \\
\text { around us }\end{array}$ & & & \\
\hline $30-34$ & & $\begin{array}{l}\text { and work together to stop } \\
\text { it. Please pledge just two } \\
\text { pounds a month to the } \\
\text { NSPCC }\end{array}$ & $\begin{array}{l}\text { /NSPCC/ £2 a month } \\
\text { appeal/Text GIVE to } \\
\text { 67766/0800802020/nspcc. } \\
\text { org.uk/give }\end{array}$ & & \\
\hline $34-41$ & $\begin{array}{l}\text { Miles standing up in the } \\
\text { corner of his cot looking } \\
\text { sadly at the camera. }\end{array}$ & $\begin{array}{l}\text { and be there for children } \\
\text { in desperate need. } \\
\text { <entreating voice> Please } \\
\text { open your eyes and your } \\
\text { heart. }\end{array}$ & $\begin{array}{l}\text { Registered charity No. } \\
216401 / \text { Text GIVE to } \\
67766 \\
\text { /0800802020/nspcc.org.u } \\
\text { k/give }\end{array}$ & & \\
\hline $41-45$ & Black screen. & $\begin{array}{l}\text { Call the NSPCC now on } \\
0800802020\end{array}$ & $\begin{array}{lr}\text { /NSPCC/Cruelty } & \text { to } \\
\text { children must stop. Full }\end{array}$ & & \\
\hline
\end{tabular}




\begin{tabular}{|c|c|c|c|c|}
\hline & & & $\begin{array}{l}\text { stop./ £2 a month appeal/ } \\
\text { Text GIVE to } \\
\text { 67766/0800802020/nspcc. } \\
\text { org.uk/give }\end{array}$ & \\
\hline $45-60$ & $\begin{array}{l}\text { Close up of Miles with teary } \\
\text { eyes looking at the camera. }\end{array}$ & $\begin{array}{l}\text { and give two pounds a } \\
\text { month or whatever you } \\
\text { can. Together we can help } \\
\text { stop cruelty to children } \\
\text { Full stop. Let us start } \\
\text { now. }\end{array}$ & $\begin{array}{l}\text { Text GIVE to } \\
\text { 67766/0800802020/nspcc. } \\
\text { org.uk/give }\end{array}$ & $\begin{array}{l}\text { Music } \\
\text { is } \\
\text { slightly } \\
\text { more } \\
\text { upbeat }\end{array}$ \\
\hline
\end{tabular}

Appendix Table 2: NSPCC- Miles/ Long version

\begin{tabular}{|c|c|c|c|c|}
\hline$\#$ & & On-Screen-Text & Dialogue & Music \\
\hline $0-4$ & $\begin{array}{l}\text { Arm of man in yellow sweater stroking } \\
\text { a happy looking dog. The dog, tells us } \\
\text { that his name is Harry. }\end{array}$ & \multirow{6}{*}{$\begin{array}{l}\text { Please sponsor a dog/ } \\
\text { DogsTrust Registered } \\
\text { Charity Numbers: } 227523 \\
\text { SC037843 }\end{array}$} & $\begin{array}{l}\text { Hi, I’m Harry. I live } \\
\text { at DogsTrust. }\end{array}$ & \multirow[t]{6}{*}{$\begin{array}{l}\text { Upbeat } \\
\text { electronic } \\
\text { clavichord }\end{array}$} \\
\hline 4-8 & $\begin{array}{l}\text { Arm of man in yellow sweater stroking } \\
\text { another dog eating from a bowl. }\end{array}$ & & \multirow{5}{*}{$\begin{array}{l}\text { Will you sponsor an } \\
\text { abandoned dog like } \\
\text { me and help them find } \\
\text { out what love really } \\
\text { is? It's only a pound a } \\
\text { week so please visit } \\
\text { sponsoradog.org.uk } \\
\text { now. }\end{array}$} & \\
\hline $8-11$ & $\begin{array}{l}\text { Woman in yellow sweater playing with } \\
\text { another dog field that jumps through a } \\
\text { hoop in a green. }\end{array}$ & & & \\
\hline $11-15$ & $\begin{array}{l}\text { Person in yellow sweater caressing a } \\
\text { puppy in his bed while he gnaws on a } \\
\text { red ball. }\end{array}$ & & & \\
\hline $15-19$ & $\begin{array}{l}\text { Person in yellow sweater caressing } \\
\text { another dog that is also in his bed. }\end{array}$ & & & \\
\hline $19-21$ & $\begin{array}{l}\text { Harry in bright sunlight. Looking } \\
\text { towards camera. }\end{array}$ & & & \\
\hline $21-23$ & $\begin{array}{l}\text { Beginning of flashback to when Harry's } \\
\text { owner left him. }\end{array}$ & $\begin{array}{l}\text { Please sponsor a } \\
\text { dog/DogsTrust Registered } \\
\text { Charity Numbers: } 227523 \\
\text { SC037843 }\end{array}$ & $\begin{array}{l}<\text { Melancholy voice }>\text { I } \\
\text { know what it's like to } \\
\text { love someone who } \\
\text { doesn't love you. I } \\
\text { loved my owner but } \\
\text { one day he }\end{array}$ & $\begin{array}{l}\text { Melancholy } \\
\text { electronic } \\
\text { clavichord }\end{array}$ \\
\hline $23-29$ & $\begin{array}{l}\text { Flashback to when his owner left him. } \\
\text { He looks out of the window of what we } \\
\text { find out later is a dirty caravan. The } \\
\text { sound of a projector. Colour darkens } \\
\text { image blurs. The camera pulls back to } \\
\text { show the dirty caravan. Harry inside } \\
\text { looking out sadly. }\end{array}$ & $\begin{array}{l}\text { Love is ... staying } \\
\text { loyal./DogsTrust/Text } \\
\text { love is to 64118/Standard } \\
\text { text charges apply/ love is } \\
\ldots \text {. Being cuddled/ love is } \\
\ldots \text {. Being safe and sound/ } \\
\text { love is . . . a sponsor like } \\
\text { you }\end{array}$ & $\begin{array}{l}<\text { Melancholy voice }> \\
\text { just left me and never } \\
\text { came back. }\end{array}$ & $\begin{array}{l}\text { Melancholy } \\
\text { electronic } \\
\text { clavichord }\end{array}$ \\
\hline $29-32$ & $\begin{array}{l}\text { Harry in what looks like a well-kept } \\
\text { garden carrying a yellow ball. }\end{array}$ & \multirow{6}{*}{$\begin{array}{l}\text { DogsTrust/Text love is to } \\
\text { 64118/Standard text } \\
\text { charges apply/ }\end{array}$} & $\begin{array}{l}\text { Luckily I was brought } \\
\text { to DogsTrust. }\end{array}$ & \multirow{6}{*}{$\begin{array}{l}\text { Upbeat } \\
\text { electronic } \\
\text { clavichord }\end{array}$} \\
\hline $32-34$ & We see another dog with a hoop. & & $\begin{array}{l}\text { They never put a } \\
\text { healthy dog down. }\end{array}$ & \\
\hline $34-37$ & $\begin{array}{l}\text { Harry again looking straight at the } \\
\text { camera. }\end{array}$ & & $\begin{array}{l}\text { When you're a } \\
\text { sponsor, your dog will } \\
\text { write and send you }\end{array}$ & \\
\hline $37-41$ & $\begin{array}{l}\text { We see a series of photos of happy } \\
\text { looking dogs (most have mouth open } \\
\text { and tongue hanging out) with their } \\
\text { names on them. }\end{array}$ & & $\begin{array}{l}\text { photos It's only a } \\
\text { pound a week so text } \\
\text { love is to } 64 \ldots\end{array}$ & \\
\hline $41-43$ & $\begin{array}{l}\text { We see a person with a yellow sweater } \\
\text { throw something for a dog to fetch. }\end{array}$ & & $\begin{array}{l}118 \text { for your free info } \\
\text { pack. }\end{array}$ & \\
\hline $43-45$ & $\begin{array}{l}\text { We see a woman in a yellow sweater } \\
\text { patting a caressing a dog. }\end{array}$ & & $\begin{array}{l}\text { DogsTrust } \\
\text { thousands of dogsue }\end{array}$ & \\
\hline
\end{tabular}




\begin{tabular}{|c|c|c|c|}
\hline & & & every year. \\
\hline $45-48$ & $\begin{array}{l}\text { We see another dog being caressed by } \\
\text { a woman in a yellow sweater. }\end{array}$ & & $\begin{array}{llll}\text { Sadly } & \text { a few } & \text { may } \\
\text { never } & \text { find a } & \text { new } \\
\text { home } & & & \\
\end{array}$ \\
\hline $48-50$ & $\begin{array}{l}\text { We see another woman in a yellow } \\
\text { sweater patting a dog in a garden. }\end{array}$ & $\begin{array}{l}\text { Love is ... being } \\
\text { cuddled./DogsTrust/Text } \\
\text { love is to 64118/Standard } \\
\text { text charges apply/ }\end{array}$ & $\begin{array}{l}\text { but here we've } \\
\text { discovered what love } \\
\text { really is. }\end{array}$ \\
\hline $50-54$ & $\begin{array}{l}\text { We see another woman in a yellow } \\
\text { sweater patting a dog in its bed. }\end{array}$ & $\begin{array}{l}\text { Love is ... being safe and } \\
\text { sound./DogsTrust/Text } \\
\text { love is to } 64118 / \text { Standard } \\
\text { text charges apply/ }\end{array}$ & $\begin{array}{l}\text { Sponsoring a dog only } \\
\text { costs a pound a week. }\end{array}$ \\
\hline $54-60$ & $\begin{array}{l}\text { We see another woman in a yellow } \\
\text { sweater caressing Harry in a garden. } \\
\text { Harry looks straight at us. }\end{array}$ & $\begin{array}{l}\text { Love is ... a sponsor like } \\
\text { you./DogsTrust/Text love } \\
\text { is to } 64118 / \text { Standard text } \\
\text { charges apply/ }\end{array}$ & $\begin{array}{l}\text { So please visit } \\
\text { sponsoradog.org.uk } \\
\text { now. Thank you. }\end{array}$ \\
\hline
\end{tabular}

Appendix Table 3: DogsTrustwww.sponsoradog.org.uk

\begin{tabular}{|c|c|c|c|c|}
\hline$\#$ & & $\begin{array}{l}\text { Voice-Over: Male/25- } \\
\text { 40/North/deep-serious }\end{array}$ & On-Screen-Text & Music \\
\hline $0-4$ & $\begin{array}{l}\text { An old lady with a } \\
\text { headscarf looks anxiously } \\
\text { into a shop window. We see } \\
\text { a label with the word } \\
\text { 'cancer' on it inside the } \\
\text { shop. Her uplifted hand } \\
\text { slowly clenches into a half } \\
\text { fist. }\end{array}$ & $\begin{array}{l}\text { When cancer causes } \\
\text { money worries, we're } \\
\text { here. }\end{array}$ & $\begin{array}{l}\text { We are Macmillan Cancer } \\
\text { Support./ } \\
\text { 0800500800./www.macmilla } \\
\text { n.org.uk/ (on lower section } \\
\text { of screen throughout) }\end{array}$ & \multirow[t]{3}{*}{$\begin{array}{l}\text { Sad, soft piano } \\
\text { and strings, } \\
\text { minor chords }\end{array}$} \\
\hline $4-12$ & $\begin{array}{l}\text { A young man is hapily } \\
\text { playing football with } \\
\text { friends. He looks at the ball. } \\
\text { It has 'cancer' written on it. } \\
\text { His expression changes to } \\
\text { one of worry. }\end{array}$ & $\begin{array}{l}\text { When you need to talk } \\
\text { to someone who } \\
\text { understands, we're here }\end{array}$ & $\begin{array}{l}\text { Macmillan Cancer Support } \\
\text { registered charity in England } \\
\text { and Wales (261017) Scotland } \\
\text { (SC03907) and The Isle of } \\
\text { Man (604)./ }\end{array}$ & \\
\hline $12-18$ & $\begin{array}{l}\text { A woman is feeding her } \\
\text { baby which is in a high } \\
\text { chair. She looks up } \\
\text { worriedly at the clock which } \\
\text { has 'cancer' written on it. }\end{array}$ & $\begin{array}{l}\text { And, when you're } \\
\text { worried about the } \\
\text { future, we're here. At } \\
\text { Macmillan Cancer } \\
\text { Support, we're here for } \\
\text { you. }\end{array}$ & & \\
\hline $18-22$ & $\begin{array}{l}\text { Then the baby laughs and } \\
\text { she smiles too. }\end{array}$ & $\begin{array}{l}<\text { VO becomes more } \\
\text { upbeat }>\text { So that some } \\
\text { days it's not all about } \\
\text { cancer. It's about life. }\end{array}$ & & \multirow[t]{2}{*}{$\begin{array}{l}<\text { music } \\
\text { becomes more } \\
\text { upbeat (major } \\
\text { chords). Ends } \\
\text { in a crescendo }>\end{array}$} \\
\hline $22-30$ & $\begin{array}{l}\text { Whitish screen followed by } \\
\text { the OST with information } \\
\text { about Macmillan. }\end{array}$ & $\begin{array}{l}\text { Call us on } 0800500800 \\
\text { or r visit } \\
\text { www.macmillan.org.uk }\end{array}$ & $\begin{array}{l}\text { We are Macmillan Cancer } \\
\text { Support./ } \\
\text { 0800500800./www.macmiilla } \\
\text { n.org.uk. (fills the screen) }\end{array}$ & \\
\hline
\end{tabular}

Appendix Table 4: MacMillan Cancer Support

\begin{tabular}{|l|l|l|l|l|}
\hline$\#$ & & $\begin{array}{l}\text { Voice-Over: } \\
\text { Male/Over } \\
\text { 40/RP/deep-serious }\end{array}$ & On-Screen-Text & Music \\
\hline $1-3$ & Black screen & $\begin{array}{l}\text { Every day 24,000 } \\
\text { children die }\end{array}$ & 24000 children will die today & $\begin{array}{l}\text { Sad Adagio } \\
\text { Adrings. } \\
\text { music. } \\
\text { type }\end{array}$ \\
\hline $3-7$ & $\begin{array}{l}\text { A woman holds a crying } \\
\text { child in her arms }\end{array}$ & $\begin{array}{l}\text { needlessly. That's 1 } \\
\text { child every 3 seconds. }\end{array}$ & & . \\
\hline
\end{tabular}




\begin{tabular}{|c|c|c|c|c|}
\hline $7-14$ & $\begin{array}{l}\text { Tanzie sits on the floor } \\
\text { looking at the people stood } \\
\text { around her and then at the } \\
\text { camera. }\end{array}$ & $\begin{array}{l}\text { Malaria kills children } \\
\text { like Tanzie. A } \\
\text { mosquito net costs just } \\
£ 3 \text { and could save her } \\
\text { life. }\end{array}$ & \#12 Mosquito net $£ 3$ & \\
\hline $14-20$ & $\begin{array}{l}\text { Aisha is crying and is } \\
\text { cuddled by her mother. }\end{array}$ & $\begin{array}{l}\text { Tiny, vulnerable Aisha } \\
\text { won't eat tonight or } \\
\text { tomorrow, she is } \\
\text { slowly dying. }\end{array}$ & & \\
\hline $20-23$ & $\begin{array}{l}\text { A child lying on a bed } \\
\text { breathing with effort. His } \\
\text { ribs are visible. }\end{array}$ & $\begin{array}{l}\text { It really doesn't have to } \\
\text { be this way. }\end{array}$ & & \multirow{6}{*}{$\begin{array}{l}\text { Adagio type } \\
\text { music does not } \\
\text { sound so sad } \\
\text { and more } \\
\text { uplifting from } \\
\text { the words 'it } \\
\text { doesn't have to } \\
\text { be theis way.' }\end{array}$} \\
\hline $23-27$ & $\begin{array}{l}\text { A child is being cared for } \\
\text { by someone. }\end{array}$ & $\begin{array}{l}\text { Please call } 0800 \quad 072 \\
9550\end{array}$ & $\begin{array}{l}0800 \quad 072 \quad 9550 / \\
\text { savethechildren.org.uk/ } \\
\text { \#25 life saving food } £ 3\end{array}$ & \\
\hline $27-29$ & $\begin{array}{l}\text { A child is eating with } \\
\text { his/her mother. }\end{array}$ & $\begin{array}{l}\text { and give just } £ 3 \text { a } \\
\text { month. }\end{array}$ & $\begin{array}{lr}0800 \quad 072 & 9550 \\
\text { savethechildren.org.uk } & / \\
\text { saving food } £ 3\end{array}$ & \\
\hline $29-33$ & $\begin{array}{l}\text { We see an African man } \\
\text { with a red Save the } \\
\text { Children t-shirt tending to } \\
\text { a child. }\end{array}$ & $\begin{array}{l}\text { Just } £ 3 \text { a month can } \\
\text { save children's lives. }\end{array}$ & $\begin{array}{ccc}0800 & 072 & 9550 / \\
\text { savethechildren.org.uk } & \end{array}$ & \\
\hline $33-35$ & $\begin{array}{l}\text { A close up of a young } \\
\text { child eating. }\end{array}$ & $\begin{array}{l}\text { We save the children, } \\
\text { will you? }\end{array}$ & & \\
\hline $35-39$ & $\begin{array}{l}\text { A white screen with the } \\
\text { OST information on it. }\end{array}$ & $\begin{array}{l}\text { Call } 08000729550 . \\
\text { Thank you. }\end{array}$ & $\begin{array}{l}\text { We save the children. Will } \\
\text { you? You can save lives with } \\
£ 3 \text { a month/08000729550 } \\
\text { savethechildren.org.uk./Save } \\
\text { the children. /Registered } \\
\text { charity England and Wales } \\
213890 \text { Scotland SCO14570 }\end{array}$ & \\
\hline
\end{tabular}

Appendix Table 5: Save the Children 


\section{References}

Arundale, Robert B., 2006. Face as relational and interactional: A communication framework for research on face, facework, and politeness. Journal of Politeness Research. Language, Behaviour, Culture 2 (2), 193-216.

Author 1, 2000. La cortesía lingüística en el discurso publicitario. Valencia: Universitat de València.

Author 1, 2011. Análisis pragmalingüístico de las estrategias de cortesía lingüística en la publicidad del siglo XXI. In: Jatobá Palacios, A. Serra, P. (Eds.), Pragmática: Comunicação Publicitária e Marketing. Livros LabCom, Portugal, Covilhã, pp. 526.

Authors, 2009. Constructing female identities through feminine hygiene TV commercials. Journal of Pragmatics 41 (12), 2535-2556.

Authors, 2011. A multimodal analysis of politeness strategies in British TV ads. Poster presented at the 12th International Pragmatics Conference. Manchester, United Kingdom, July 3-8.

Baldry, Anthony, 2004. Phase and transition, type and instance: patterns in media texts as seen through a multimodal concordancer. In: O’Halloran, K. (Ed.), Multimodal Discourse Analysis: Systemic Functional Perspectives. London and New York: Continuum, pp. 83-108.

Baldry, Anthony and Thibault, Paul, 2006. Multimodal Transcription and Text Analysis: A Multimedia Toolkit and Coursebook. Equinox, London/Oakville.

Barnett, Julie and Hammond, Sean, M., 1999. Representing disability in charity promotions. Journal of Community \& Applied Social Psychology 9, 309-314.

Bowker, Lynne and Pearson, Jennifer, 2002. Working with Specialized Language: A Practical Guide to Using Corpora. London: Routledge.

Burnett, Melissa S., and Lunsford, Dale A., 1994. Conceptualizing Guilt in the Consumer Decision-Making Process. Journal of Consumer Marketing 11 (3), 33-43.

Brown, Penelope, 1998. How and why are women more polite: some evidence from a Mayan community. In: Coates, Jennifer (Ed.), Language and Gender: A Reader. Blackwell, Oxford, pp. 81-99.

Brown, Penelope, and Levinson, Stephen D., 1987. Politeness: Some Universals in Language Usage. Cambridge: Cambridge University Press.

Chang, Chun-Tuan, and Lee, Yu-Kang, 2011. The 'I' of the beholder: How gender differences and self-referencing influence charity advertising. International Journal of Advertising 30 (3), 447-478.

Cook, Guy, 2001. The Discourse of Advertising. 2nd ed. New York: Routledge.

Cooke, Deryck, 1959. The Language of Music. Oxford: Oxford University Press.

Crook, John, 2004. On covert communication in advertising. Journal of Pragmatics 36 (4), $715-738$.

Culpeper, Jonathan, 2011. Impoliteness. Using Language to Cause Offense. Cambridge: Cambridge University Press.

Durkheim, Emile, 1915. The Elementary Forms of the Religious Life. London: George Allen and Unwin. 
Eayrs, Caroline B. and Ellis, Nick, 1990. Charity advertising: for or against people with a mental handicap? British Journal of Social Psychology 29 (4), 349-366.

Eayrs, Caroline B. and Ellis, Nick, Jones, Robert S. P. and Miller, Beth, 1995. Representations of learning disability in the literature of charity campaigns. In; Marková, I. and Farr, R. (Eds.), Representations of Health, Illness and Handicap. Harwood Academic, London, pp. 67-89.

Eelen, Gino, 2001. A Critique of Politeness Theories. Manchester: St Jerome.

Forceville, Charles, 2007. Review of Anthony Baldry \& Paul J. Thibault, Multimodal Transcription and Text Analysis: A Multimedia Toolkit and Coursebook. (Equinox 2006). Journal of Pragmatics 39 (2007) 1235-1238.

Fukada, Atsushi, and Asato, Noriko, 2004. Universal politeness theory: application to the use of Japanese honorifics. Journal of Pragmatics 36 (11), 1991-2002.

Goffman, Erving, 1955. On face-work: An analysis of ritual elements in social interaction. Psychiatry: Journal for the Study of Interpersonal Processes, 18, 213-231.

Goffman, Erving, 1956. The nature of deference and demeanor. American Anthropologist, 58, 473-502.

Goffman, Erving, 1967. Interactional Ritual: Essays on Face to Face Behaviour. Garden City, New York.

Goffman, Erving, 1969. The Presentation of Self in Every Day Life. Doubleday: Garden City, New York.

Goodwin, Charles, Duranti, Alessandro, 1992. Rethinking context: an introduction. In: Duranti, Alessandro, Goodwin, Charles (Eds.), Rethinking Context: Language as an Interactive Phenomenon. Cambridge University Press, Cambridge, pp. 1-42.

Halliday, Michael A.K., 1985. An Introduction to Functional Grammar. London: Arnold.

Hasegawa, Yoko, 2008. Simultaneous application of negative and positive politeness. Proceedings from the Annual Meeting of the Chicago Linguistic Society 44 (4), 125-140.

Haverkate, Henk, 1994. La cortesía verbal. Estudio pragmalingüístico. Madrid, Gredos.

He, Ming and Zhang, Shao-Jie, 2011. Re-conceptualizing the Chinese concept of face from a face-sensitive perspective: A case study of a modern Chinese TV drama. Journal of Pragmatics 43 (9), 2360-2372.

Hevey, David, 1992. The Creatures Time Forgot: Photography and Disability Imagery. Routledge, London.

Hibbert, Sally, Smith, Andrew, Davies, Andrea and Ireland, Fiona, 2007. Guilt Appeals: Persuasion Knowledge and Charitable Giving. Psychology and Marketing 24 (8), 723-742.

Hill, Jane H., Irvine, Judith T., 1992. Introduction. In: Hill, Jane H., Irvine, Judith T. (Eds.), Responsibility and Evidence in Oral Discourse. Cambridge University Press, Cambridge, pp. 1-23.

Huhmann, Bruce A. and Brotherton, Timothy P., 1997. A Content Analysis of Guilt Appeals in Popular Magazine Advertisements. Journal of Advertising 26 (2), 35-45.

Hyman, Michael R. and Tansey, Richard, 1990. The Ethics of Psychoactive Ads. Journal of Business Ethics 9 (2), 105-114.

Ide, Sachiko, 1989. Japanese sociolinguitics: Politeness and women’s language. Lingua 577: 357-385. 
Jantzen, Christian and Stiegel, Jørgen, 1995. Reklamen i Landsdækkende tv. København: Statsministeriets Medieudvalg.

Kress, Gunter and Teo, van Leeuwen, 1996. Reading Images: The Grammar of Visual Design. London: Routledge.

Larsen, Val, 2005. The timely and the timeless: Syntagmatic and paradigmatic sign relations in advertising montage. Advances in Consumer Research 32: 162-163.

Levinson, Stephen C., 1983. Pragmatics. Cambridge University Press, Cambridge.

MacKenzie, Scott B. and Richard J., Lutz, 1989. An empirical examination of attitude toward the ad in an advertising pretest context. Journal of Marketing 53, 48-65.

Machin, David, 2010. Analysing Popular Music: Image, Sound, Text. London: Sage.

Matsumoto, Yoshiko, 1988. Reexamination of the universality of face: Politeness phenomena in Japanese. Journal of Pragmatics 12 (4), 403-426.

Mills, Sara, 2005. Gender and Colonial Space. Manchester University Press.

Moore, David, J., and Harris, William, D., 1996. Affect Intensity and The Consumer's Attitude Toward High Impact Emotional Advertising Appeals. Journal of Advertising 25 (2), 37-50.

Messaris, Paul, 1997. Visual Persuasion: The Role of Images in Advertising. Thousand Oaks, Cal.: Sage.

Nelson, Michelle, R., Brunel, Frédéric F., Supphellen, Magne and Manchanda, Raj V., 2006. Effects of culture, gender, and moral obligations on responses to charity advertising across masculine and feminine cultures. Journal of Consumer Psychology 16, 45-56.

O’Driscoll, Jim, 2007. Brown and Levinson's face: How it can-and can't-help us to understand interaction across cultures. Intercultural Pragmatics 4/4: 463-492.

Poyatos, Fernando 2002. Nonverbal Communication across Disciplines: Culture, sensory interaction, speech, conversation. (Vol. 1) Amsterdam: John Benjamins.

Sbisà, Marina, 2001. Illocutionary force and degree of strength in language use. Journal of Pragmatics 33, 1791-1814.

Scott-Parker, Susan 1989. They Aren't in the Brief, King's Fund Centre, London.

Smith, Gerald E., and Berger, Paul D., 1996. The impact of direct marketing appeals on charitable marketing effectiveness. Journal of the Academy of Marketing Science 24, 219-231.

Stigel, Jørgen 2001. TV Advertising Virtually Speaking: The Invisible Voice Elaborating on the Space between Screen and Viewer. In: Gunhild, A. and Jensen, J. F. (Eds.), The Aesthetics of Television. Aalborg: Aalborg UP, pp. 321-348.

Streeck, Jurgen, 1980. Speech acts in interaction: a critique of Searle. Discourse Processes 3, 133-154.

Tagg, Philip, 1982. Nature as a Musical mood category, Norden’s working paper series (http://www.tagg.org/articles/xpdfs/nature.pdf).

Thibault, Paul John, 2000. The multimodal transcription of a television advertisement: theory and practice. In: Baldry, A. (Ed.), Multimodality and Multimediality in the Distance Learning Age. Campobasso: Palladino Editore, pp. 311-385.

Van Leeuwen, Teo J., 1999. Speech, Music, Sound. London: McMillan.

Watts, Richard, 2003. Politeness. Cambridge University Press: Cambridge. 
Watts, Richard, 2008. Rudeness, conceptual blending theory and relational work. Journal of Politeness Research, 4 (2), 289-317.

Wee, Lionel, 2004. 'Extreme communicative acts' and the boosting of illocutionary force. Journal of Pragmatics 36, 2161-2178.

Williamson, Judith, 1978. Decoding Advertisements: Ideology and Meaning in Advertisements. London: Maryon Boyars.

Wilson, Deirdre and Wharton, Tim, 2006. Relevance and prosody. Journal of Pragmatics 38(10), 1559-1579.

Yu, Ming-Chung, 2003. On the universality of face: Evidence from Chinese compliment response behavior. Journal of Pragmatics 35 (10-11), 1679-1710. 